\title{
MANGANÊS E POTENCIAL FISIOLÓGICO DE SEMENTES DE SOJA
}

\author{
MANGANESE AND PHYSIOLOGICAL QUALITY OF SOYBEAN SEEDS
}

\author{
Marcelo Melarato ${ }^{1}$ Maristela Panobianco ${ }^{2}$ \\ Godofredo Cesar Vitti ${ }^{3}$ Roberval Daiton Vieira ${ }^{4}$
}

\section{- NOTA -}

RESUMO

O trabalho teve por objetivo avaliar a influência de diferentes fontes e modos de aplicação de manganês, em plantas de soja, sobre o potencial fisiológico das sementes produzidas e a massa de mil sementes. Os tratamentos constaram de fontes de manganês aplicadas via solo $\left(\mathrm{MnSO}_{4} .4 \mathrm{H}_{2} \mathrm{O}\right.$ e Oxi-sulfato $\left.\mathrm{Mn}\right) \mathrm{e}$ via foliar $\left(\mathrm{MnSO}_{4} .4 \mathrm{H}_{2} \mathrm{O}\right.$, Quelado $\mathrm{Cl}$, Quelado $\mathrm{NO}_{3}^{-}$e Quelado $\left.\mathrm{SO}_{4}^{2-}\right)$; para as sementes produzidas, determinaram-se a massa de mil sementes, a germinação e o vigor (envelhecimento acelerado e condutividade elétrica). Diante dos resultados obtidos, concluiu-se que a aplicação de manganês exerceu influência positiva sobre a massa das sementes de soja produzidas e que o estado nutricional das plantas, em relação ao manganês, não influenciou o potencial fisiológico das sementes produzidas.

Palavras-chave: Glycine max, micronutrientes, vigor, germinação.

\section{SUMMARY}

This work was carried out in order to study the influence in soybean crop of manganese applying, using different source and way, on the physiological potential of produced seeds and the weight of 1000 seeds. The treatments consisted of two sources $\left(\mathrm{MnSO}_{4} \cdot 4 \mathrm{H}_{2} \mathrm{O}\right.$ and $\mathrm{Mn}$ Oxi-Sulphate) applied into the soil and four sources $\left(\mathrm{MnSO}_{4} 4 \mathrm{H}_{2} \mathrm{O}\right.$, chelate $\mathrm{Cl}$, chelate $\mathrm{NO}_{3}^{-}$and chelate $\mathrm{SO}_{4}^{2-}$ ) applied through the leaves. Using the produced seeds the standard germination, weight of 1000 seeds and vigor as accelerated aging and electrical conductivity were evaluated. Based on these results it can be concluded that there was a positive effect of the applied Mn on the weight of 1000 seeds and that the physiological potential of seeds wasn't influenced by the manganese supply.

Key words: Glycine max, micronutrients, vigor, germination.

O manganês desempenha funções importantes na vida da planta. Entre essas, estão a ativação de enzimas e a participação na reação de fotólise da água e na evolução do $\mathrm{O}_{2}$ no sistema fotossintético, na formação de clorofila e na formação, multiplicação e funcionamento dos cloroplastos. Além disso, atua também no metabolismo do nitrogênio e nos compostos cíclicos, como precursor de aminoácidos, hormônios, fenóis e ligninas.

As funções de ativação enzimática, biossíntese, transferência de energia e regulação hormonal são fundamentais para formação, desenvolvimento e maturação das sementes e, assim, tanto macro quanto micronutrientes apresentam importância similar nos referidos eventos. Neste sentido, o manganês, pela sua natureza, pode estar envolvido, direta ou indiretamente, na qualidade fisiológica das sementes produzidas (Tabela 1).

${ }^{1}$ Engenheiro Agrônomo, Doutor.

${ }^{2}$ Engenheiro Agrônomo, Doutor.

${ }^{3}$ Engenheiro Agrônomo, Doutor, Professor Titular do Departamento de Solos e Nutrição de Plantas, Escola Superior de Agronomia Eliseu Maciel, Universidade de São Paulo.

${ }^{4}$ Engenheiro Agrônomo, Doutor, Professor Titular do Departamento de Produção Vegetal, Faculdade de Ciências Agrárias e Veterinárias, Universidade Estadual Paulista. Via de Acesso Professor Paulo Donato Castellane, s/n, 14884-900, Jaboticabal, SP. Bolsista CNPq. E-mail: rdvieira@fcav.unesp.br. Autor para correspondência. 
Tabela 1 - Massa de mil sementes (corrigida para 13\% de água), grau de umidade inicial e após o envelhecimento acelerado (EA), germinação e vigor, avaliado pelos testes de envelhecimento acelerado (EA) e de condutividade elétrica (CE), de sementes de soja, cultivar Garimpo.

\begin{tabular}{|c|c|c|c|c|c|c|}
\hline \multirow{2}{*}{ Tratamento } & \multirow{2}{*}{$\begin{array}{l}\text { Massa de mil } \\
\text { sementes }\end{array}$} & \multicolumn{2}{|c|}{ Grau de umidade } & \multirow{2}{*}{ Germinação } & \multicolumn{2}{|c|}{ Vigor } \\
\hline & & inicial & Após EA & & EA & $\mathrm{CE}$ \\
\hline & $\mathrm{g}$ & & & & & $\mu S . \mathrm{cm}^{-1} \cdot \mathrm{g}^{-1}$ \\
\hline T1- Testemunha & $107,0 b^{*}$ & 10,0 & 28,5 & $84 \mathrm{a}$ & $82 \mathrm{a}$ & $81,7 \mathrm{~b}$ \\
\hline $\mathrm{T} 2-\mathrm{MnSO}_{4} \cdot 4 \mathrm{H}_{2} \mathrm{O}\left(350 \mathrm{~g} \mathrm{ha}^{-1}\right)$ - foliar & $123,2 \mathrm{a}$ & 10,3 & 28,1 & $94 \mathrm{a}$ & $88 \mathrm{a}$ & $63,8 \mathrm{a}$ \\
\hline T3- $\mathrm{MnSO}_{4} \cdot 4 \mathrm{H}_{2} \mathrm{O}\left(200 \mathrm{~g} \mathrm{ha}^{-1}\right)$ - foliar & $120,8 \mathrm{a}$ & 10,0 & 28,1 & $91 \mathrm{a}$ & $86 \mathrm{a}$ & $66,6 \mathrm{a}$ \\
\hline T4- Quelado $\mathrm{Cl}^{-}\left(200 \mathrm{~g} \mathrm{~h}^{-1}\right)$ - foliar & $122,9 \mathrm{a}$ & 9,9 & 27,9 & $95 \mathrm{a}$ & $87 \mathrm{a}$ & $66,0 \mathrm{a}$ \\
\hline T5- Quelado $\mathrm{NO}_{3}^{-}\left(200 \mathrm{~g} \mathrm{ha}^{-1}\right)$ - foliar & $120,8 \mathrm{a}$ & 10,0 & 28,0 & $91 \mathrm{a}$ & $87 \mathrm{a}$ & $65,0 \mathrm{a}$ \\
\hline T6- Quelado $\mathrm{SO}_{4}{ }^{2-}\left(200 \mathrm{~g} \mathrm{ha}^{-1}\right)$ - foliar & $122,5 \mathrm{a}$ & 10,0 & 27,5 & $90 \mathrm{a}$ & $87 \mathrm{a}$ & $64,8 \mathrm{a}$ \\
\hline T7- $\mathrm{MnSO}_{4} \cdot 4 \mathrm{H}_{2} \mathrm{O}\left(4000 \mathrm{~g} \mathrm{ha}^{-1}\right)$ - solo & $121,2 \mathrm{a}$ & 9,0 & 27,0 & $91 \mathrm{a}$ & $84 \mathrm{a}$ & $74,5 \mathrm{ab}$ \\
\hline T8- Oxi-sulfato Mn $\left(4000 \mathrm{~g} \mathrm{ha}^{-1}\right)$ - solo & $117,7 \mathrm{a}$ & 9,2 & 27,7 & $92 \mathrm{a}$ & $87 \mathrm{a}$ & $74,7 \mathrm{ab}$ \\
\hline C.V. $(\%)$ & 3,04 & - & - & 7,98 & 8,15 & 9,30 \\
\hline
\end{tabular}

*Médias não seguidas pela mesma letra, na coluna, diferem entre si pelo teste de Tukey, a 5\% de probabilidade de erro.

O presente trabalho teve por objetivo avaliar a influência de diferentes fontes e modos de aplicação de manganês, em plantas de soja, sobre o potencial fisiológico das sementes produzidas e a massa de mil sementes.

O experimento de campo foi conduzido do final do mês de novembro de 1998 (semeadura) até meados do mês de março de 1999 (colheita), em área de produção de soja (sistema plantio direto) na região de cerrado, localizada no município de Uberaba, MG, onde a ocorrência de deficiência de manganês vinha sendo constatada. Foram utilizadas sementes do cultivar Garimpo.

Os tratamentos constaram de fontes de manganês aplicadas via solo e foliar (Tabela 1). Foram feitas duas aplicações dos tratamentos via foliar (T2, T3, T4, T5 e T6): a primeira, quando a maioria das plantas estava no estádio $\mathrm{V}_{4}$ (FEHR \& CAVINESS, 1977) e, a segunda, quando a maioria das plantas estava no estádio $R_{1}$.

A avaliação da qualidade das sementes foi efetuada no Laboratório de Análise de Sementes do Departamento de Produção Vegetal da USP/ESALQ, em Piracicaba, SP. As sementes foram submetidas aos seguintes testes: determinação do grau de umidade: (BRASIL, 1992); massa de mil sementes (BRASIL, 1992); germinação (BRASIL, 1992); envelhecimento acelerado (MARCOS FILHO, 1999) e condutividade elétrica (VIEIRA, 1994).

Com relação à massa de mil sementes, pode-se verificar um agrupamento das médias, sendo que as plantas da testemunha produziram sementes mais leves do que aquelas dos demais tratamentos, que, por sua vez, não diferiram entre si. Esses resultados indicaram que a aplicação de manganês, tanto via foliar quanto via solo, exerceu influência positiva sobre a massa das sementes de soja produzidas. O grau de umidade das sementes foi, de modo geral, semelhante para os tratamentos estudados.

Pelos resultados dos testes de germinação e de envelhecimento acelerado, pode-se notar que não foram detectadas diferenças entre os tratamentos, indicando que as fontes e modos de aplicação de manganês utilizados não ocasionaram aumento no vigor das sementes. Por outro lado, o teste de condutividade elétrica identificou os tratamentos aplicados via foliar como superiores, embora não tenham diferido estatisticamente dos tratamentos aplicados via solo, os quais, por sua vez, mostraram-se semelhantes à testemunha, apontada como o tratamento de pior desempenho.

Uma hipótese para justificar as diferenças entre tratamentos, exibidas no teste de condutividade elétrica, baseia-se no fato de que o manganês está envolvido na formação da lignina, uma das substâncias presentes na parede celular que apresenta características de impermeabilização, podendo exercer, conseqüentemente, efeito significativo sobre a capacidade e a velocidade de absorção de água através do tegumento, alterando desse modo a quantidade de lixiviados liberados para o meio externo (PANOBIANCO et al., 1999). Estes autores verificaram que teores mais baixos de lignina no tegumento de sementes de soja relacionaram-se a valores mais altos de condutividade elétrica.

A aplicação de manganês exerceu influência positiva sobre a massa das sementes de soja produzidas e o estado nutricional das plantas de soja, em relação ao manganês, não influenciou o potencial fisiológico das sementes produzidas. 


\section{REFERÊNCIAS BIBLIOGRÁFICAS}

BRASIL. Ministério da Agricultura. Regras para análise de sementes. Brasília : SNDA/DNDV/CLAV, 1992. 365p.

FEHR, W.R., CAVINESS, C.E. Stages of soybean development. Ames : Iowa State University of Science and Technology, 1977. 11p.

MARCOS FILHO, J. Teste de envelhecimento acelerado. In: KRZYZANOWSKI, F.C., VIEIRA, R.D., FRANÇA NETO,
J.B. (Ed.). Vigor de sementes: Conceitos e testes. Londrina: ABRATES, 1999. Cap.3, p.1-24.

PANOBIANCO, M., VIEIRA, R.D., KRZYZANOWSKI, F.C., et al. Electrical conductivity of soybean seed and correlation with seed coat lignin content. Seed Science and Technology, v.27, n.3, p.945-949, 1999.

VIEIRA, R.D. Teste de condutividade elétrica. In: VIEIRA, R.D., CARVALHO, N.M. (Ed.). Testes de vigor em sementes. Jaboticabal : FUNEP, 1994. p.103-132. 